\title{
Accreditation of Engineering Education through Curriculum Development in Australia
}

\author{
http://dx.doi.org/10.3991/ijep.v3iS4.3147 \\ H. Edalatifard and E. Prieto \\ The University of Newcastle, NSW, Australia
}

\begin{abstract}
Due to emerging technological developments, the practice of engineering is changing remarkably. One of the main concerns of engineering education is to keep up with these revolutionary changes and incorporate them into the engineering curriculum. Social and professional needs have always been involved in the process of curriculum development and competencies set by professional organisations form a reference point for educational institutions. In this paper we argue that academics and administrators in universities are at the heart of change in their role as curriculum developers and implementers. We also propose that matching academic skills with the competencies / standards set by professional organisations can help pave the way in fast evolving technical fields.
\end{abstract}

Index Terms-Curriculum Development; Competencies; Engineers Australia

\section{INTRODUCTION}

Engineering Education provides a research framework to overcome economic, cultural, and social challenges by associating engineering profession, society, educational organisations, educators and students to respond the requirement of society. It does not only refer to how people learn engineering, it is a diverse field of research attempting to adapt and harmonize social, industrial, technological and professional requirements. Continuous improvements in engineering education will assist achieving this attempt. According to recent literature [1] curriculum development is one of the most direct and efficient ways to improve engineering education. Along the same lines it is stated that curriculum development is at the heart of engineering education [2]. Curriculum is important as it not only constitutes the infrastructure of educational endeavours, but also reflects educational goals, objectives and links to the world around us. Curriculum development is a complex obligation involving a wide variety of knowledge, and needs skillful change agents in order to take place $[2,3]$. Particularly in higher education, curriculum is highly committed to social, community, political and cultural issues [4-6]. Therefore, there is a need to ensure that curriculum provides all knowledge and skills for the relevant discipline and meets all required standards for the profession.

Scrutiny of the current curricula in most technical fields reveals that these curricula do not include practical and up-to-date practices [7-9]. Curriculum overload [10] and lack of inclusivity [11] have been noted as potential issues in engineering curricula in recent years. Curriculum greatly affects student engagement in engineering degrees. Statistics show that numbers of students in engineering are decreasing [12]. The average national graduation success rate for engineering in Australia has been reported between $54 \%$ [13] and $65 \%$ [11] due to the fact of a relatively high rate of attrition for engineering [13]. Indeed, when individuals do not find a rational connection between the curriculum studied in their university course and their future careers, their motivation to commence and continue in engineering is decreased. Therefore, "changes in degree structure and curriculum, and academic and social support strategies, are likely to contribute to improving retention and graduation rates" [14, p. 4].

On the other hand, this perceived lack of relevance of a curriculum might be one of the reasons for the engineering industry to import overseas workers as their needs are not being met by local university graduates. Although, universities and training institutions do have a high commitment to supply the required proficient graduates, other parties can have a critical role as well. For instance, professional organisations who provide standards for practices undertake a significant role [15] since these standards are essential to carry on the development and improvement of the practice. Reforming the curriculum does not completely solve the problem, but bringing industry and universities together can result in a plan to fill the gaps. Also, university programs can provide skilled employees which really met industry needs [8]. This issue is being argued especially for fast-growing fields, when they are increasingly faced with changes and challenges, and as [8] argue it is not easy for academic institutions to keep up with these changes quickly.

\section{CURRiculum DeVelopment At The HeArt OF ENGINEERING EDUCATION}

Due to emerging technology developments, the practice of engineering is changing. One of the concerns of engineering education as a field is to follow these revolutionary changes and incorporate them into engineering curricula. It has been noted that "changes in society tend to immediately require corresponding changes in the curriculum of higher education institutions presumably because it is the end of formal education and the last opportunity for entry into the world of work" [6, p. 10]. This approach will make the quality of engineering education secure in the $21^{\text {st }}$ century. However, "reformers have proposed improvements in engineering education for several decades yet there have been few conceptual advances in the curriculum since it became largely based on engineering science in the 1960s" [16, p. 378].

The issue of curriculum development has been considered from different perspectives throughout history. Literature $[17,18]$ shows that a range of factors influence the development of curriculum such as: social conditions, 
the influence of public, professional associations and agencies, schools and universities, political influences in different levels (federal/ state), test agencies and publishers. Apart from the knowledge development and pedagogy, examining the process of curriculum development in older literature [19] indicates that the society and its related issues played the vital role in this process:

- The function of education in terms of culture transmission and individual development

- The analysis of society in terms of the impact of science and technology

- The analysis of culture in terms of values and culture change

- Learning theories

- The process of development in terms of readiness and relationship with the areas of development

- The nature of knowledge

Curriculum can be used as a moderator tool for society since the content of curriculum is refleting the needs and requirements of society. When curriculum is being developed based on the demands of society, then students will learn align with the society's need. "If curriculum is to be a useful prescription for learning, its content and the outcomes it pursues need to be in tune with the social and cultural realities of the times" [19, p. 272]. This will benefit both individuals and society. On the individual side, finding a career in future might be easier since it will line up with societal requirements. On the social perspective, it will fill the identified gaps by training the required professionals. Unemployment in educated parts of population might be the result of incorect policy in curriculum development in higher education. Advantages of developing curriculum based on society needs include [19]:

- Providing a balance between supply and demand in society

- Facilitating learning by the usage of experiential background

- Permitting the overview of society for all variety of discipline

- Providing an explicit approach for curriculum development

- Providing a trustworthy source for value orientation in society

Here is an example of curriculum change based on social conditions: during the last decade Iranian government was faced to a crisis of overpopulation. In order to resolve the issue, curriculum was used to increase the general awarness about control population. As a compulsary course, students at higher education level learnt how to birth control choices and methods of contrapception. In fact, curriculum is a key moderator and "a way to respond to the challenges of contemporary society" [4, p. 10]. This will support the argument proposed in [6] that the demands of society are the first stage in curriculum development.

Thus, due to knowledge expansion, tertiary education must keep pace with societal needs by frequently performing curriculum revision and development [6]. Keeping in mind society's need, recent literature shows a switch to curriculum redesign in higher education. Issues associated with this redesign are:

- Following the recent technological developments by improving the current curriculum $[6,20]$

- Filling the current gaps in higher educational programms [6]

- Considering the needs of society [6]

- Providing more focus and flexibility by weeding out the unnecessary workload and increase engagement $[20,21]$

- Reconsidering the enginerring requirements to allow other students to switch into engineering [22]

- Increasing retention and sustainability [13]

\section{POSSIBILITIES FOR IMPROVEMENT}

In the field of curriculum development, the need for a theory has been acknowledged in the literature. However, "such a theory should not only define the problems with which curriculum development must deal, but also elaborate the system of concepts which must be used to assess the relevance of these data to education" [19, p. 6]. Literature on curriculum development shows that a huge range of models have been adopted by curriculum designers in order to provide an inclusive curriculum: The curricula schema [23], the model for systematizing the curriculum development [24], the $3 \mathrm{p}$ model of curriculum [5], the process model for curriculum revision [25], and the process model for curricula change in engineering education [26].

Obviously, a range of different factors influence curriculum development, however social and professional needs have always been involved in this process. In modeling of engineering curriculum process it is acknowledged that identifying the problem by focusing on industrial, social, and professional needs must be considered at the first stage of summative evaluation [27]. Another model is proposed for determining typical influences on engineering curriculum, which "is not exhaustive in its inclusions but does highlight a range of elements needing consideration when reflecting on curriculum" [5, p. 9]. The article claims that the model reflects the current arrangements in Australian universities and shows a significant consideration to the role of change agents such as curriculum review committee, course co-ordinator and lecturers as well as professional requirements.

In the field of engineering education, curriculum requires a continuous improvement and update. Standards and competencies set by professional organisations form a reference point for educational institutions to apply those standards in their curriculum. As [1, p. 42] states "engineering educators have a responsibility to society and to their students to give their students the best possible opportunity to develop the competencies they will require to become successful engineers".

In the Competencies of Engineering Graduate (CEG) project, [1] provides 11-factor competencies (including inter-related technical and non-technical components) required by engineers graduating in Australia: Communication, Teamwork, Professionalism, Self-management, Ingenuity, Management and Leadership, Engineering Business, Entrepreneurship, Practical Engineering, Professional Responsibilities, and Applying Technical Theory. Although, the article advocates that these components are 


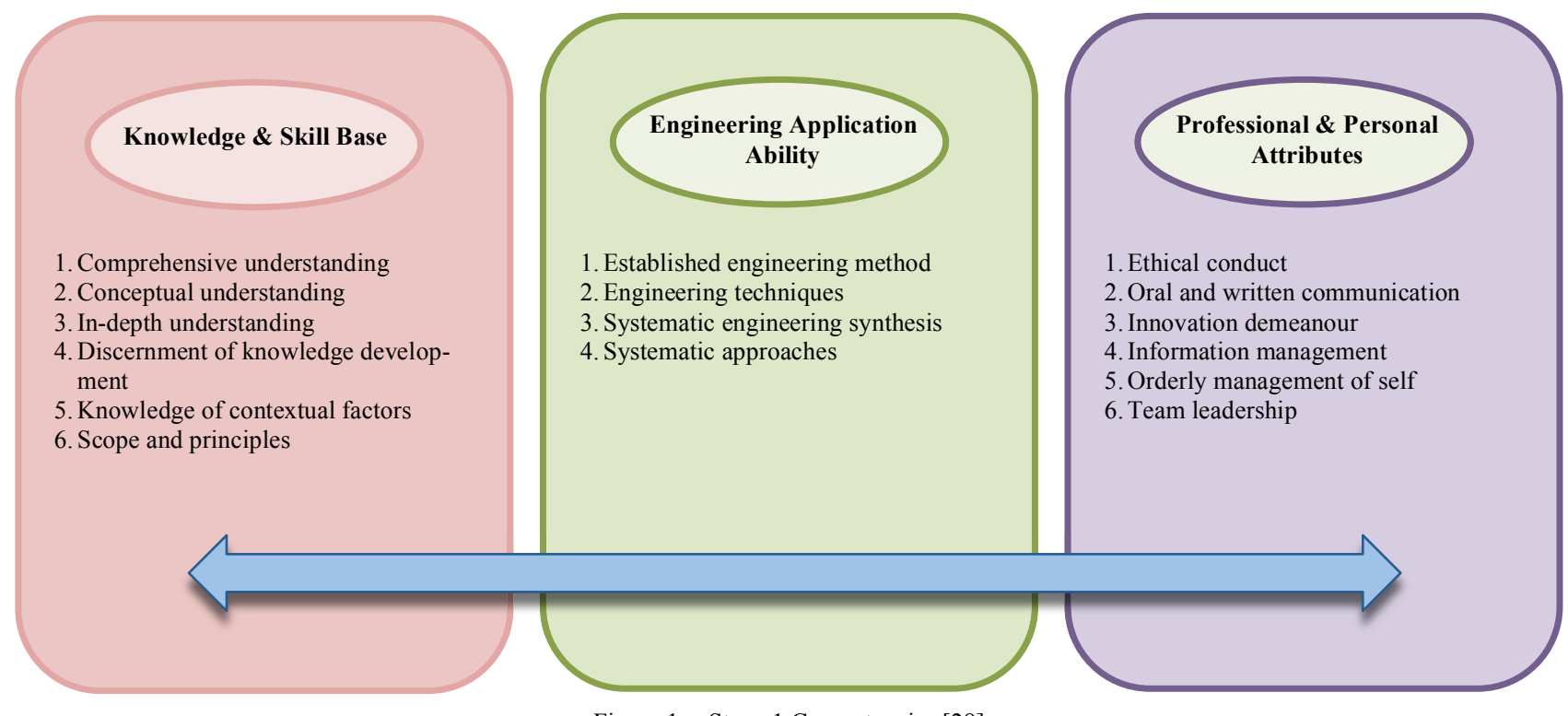

Figure 1. Stage 1 Competencies [28]

more distinct than items currently stipulated for accrediting engineering education programs, the Council of Engineers Australia has already (February 2011) developed and approved the National Generic Stage 1 Competency Standards for professional engineers [28]. Professional engineers require these competencies to commence practice. Moreover, according to Engineers Australia [28], these competencies must be used as an educational reference from the beginning of 2013. These standards are covered by 16 mandatory Elements of Competency (Figure 1). As can be seen it contains 3 groups of interconnected competencies: Knowledge and Skill base, Engineering Application Ability, and Professional and Personal Attributes. These competencies are required to be demonstrated prior to start practice as a professional engineer. As Engineers Australia [28] states, these elements "guide the competency demonstration and assessment processes as well as curriculum design".

\section{CONCLUSION AND SUGGESTIONS}

In order to be at the forefront of global scientific and technological advancement, it is essential for Australian academia to attend to this advancement in their curricula. To achieve the above-mentioned goal, competencies which are superposed by professional organisations (such as Engineers Australia) have a critical role. In this case, it is crucial to identify the position of competencies in the process of curriculum development. If there is not enough evidence of these competencies in the current curriculum, then why and what are the barriers and potential issues? Moreover, academics in universities are the key to change in their role as curriculum developers and implementers. A match between academic skills comprised in tertiary education curricula and the competencies set by professional organisations can help pave the way in fast evolving technical fields.

\section{REFERENCES}

[1] [1] S. A. Male, "Generic Engineering Competencies Required by Engineers Graduating in Australia: The Competencies of Engineering Graduates (CEG) Project", in Developments in Engineering Education Standards: Advanced Curriculum
Innovations, M. Rasul, Editor. 2012. p. 41-63. http://dx.doi.org/10.4018/978-1-4666-0951-8.ch003

[2] [2] I. Cameron and G. Birkett, "A curriculum design, modelling and visualization environment", in 23rd Annual Conference of the Australasian Association for Engineering Education (AAEE), L. Mann and S. Daniel, Editors. 2012: Melbourne, Australia.

[3] [3] L. Jollya, L. Brodieb, J. K. Prpicc, C. Crosthwaitea, L. Kavanagha, and L. Buys, "Curriculum Development and Educational Research: the barriers to good practice and what to do about them", in 23rd Annual Conference of the Australasian Association for Engineering Education (AAEE), L. Mann and S. Daniel, Editors. 2012: Melbourne, Australia.

[4] [4] M. Marita and A. Johanna, "Meanings behind curriculum development in higher education". Tampub - The Institutional Repository of University of Tampere, 2010: p. 9-24.

[5] [5] O. Hicks. "Curriculum in higher education in Australia Hello?". in Enhancing Higher Education, Theory and Scholarship, Proceedings of the 30th HERDSA Annual Conference. 2007. Adelaide, Australia: Higher Education Research and Development Society of Australasia, Inc.

[6] [6] J. Shabani, P. Obanya, and P. Okebukola, "Curriculum Development in Higher Education", in Guide to Teaching and Learning in Higher Education in Africa. 2000, UNESCO.

[7] [7] E. Robert, "Computing education and the information technology workforce". 2000, National Acadamy Study on Workforce Needs in Information Technology.

[8] [8] J. L. Bailey and G. Stefaniak. "Preparing the information technology workforce for the new millennium". in In Proceedings of the 2000 ACM SIGCPR conference on Computer personnel research. 2000. New York, USA, 2000.

[9] [9] G. R. Lowry, "Information Systems and Technology Education: From the University to the Workplace". 2007: IGI Global.

[10] [10] B. F. French, J. C. Immekus, and W. C. Oakes, "An Examination of Indicators of Engineering Students' Success and Persistence". Journal of Engineering Education, 2005. 94(4): p. 419- 425. http://dx.doi.org/10.1002/j.2168-9830. 2005.tb00869.x

[11] [11] E. Godfrey and R. King, "Curriculum specification and support for engineering education: understanding attrition, academic support, revised competencies, pathways and access". 2011, Australian Council of Engineering Deans.

[12] [12] R. Gabb, L. Milne, and Z. Cao, "Understanding attrition and improving transition a review of recent literature". Postcompulsory Education Centre, Victoria University, Melbourne., 2006. 
[13] [13] R. King, "Addressing the Supply and Quality of Engineering Graduates for the New Century". 2008, The Australian Council of Engineering Deans (ACED).

[14] [14] R. King and E. Godfrey, "Understanding and Reducing Attrition in Engineering Education", in Knowing Your Students: cohort analysis and decision trees as tools to understanding attrition. 2011, University of Technology Sydney, The University of Queensland Australia \& Australian Council of Engineering Dean.

[15] [15] B. Trendle, "Skill and labour shortages - definition, cause and implications", in Celever.Skilled. Creative, L.M.R. Unit, Editor. 2008, Department of Education, Training and the Arts: Queensland.

[16] [16] J. Trevelyan, "Why Do Attempts at Engineering Education Reform Consistently Fall Short?", in 23rd Annual Conference of the Australasian Association for Engineering Education (AAEE), L. Mann and S. Daniel, Editors. 2012: Melbourne, Australia.

[17] [17] K. Wiles and W. Sugg, "Factors Influencing Curriculum Development". Review of Educational Research, 1954. 24(3): p. 195-203.

[18] [18] D. Tanner and L. Tanner, "Curriculum Development: Theory Into Practice (3rd Edition)". 1995, New Jersey: Macmillan Publishing Co.

[19] [19] H. Taba, "Curriculum development; theory and practice". 1962: New York, Harcourt, Brace \& World.

[20] [20] J. J. Duderstadt, "Engineering for a Changing World: A Roadmap to the Future of Engineering Practice, Research, and Education", in The Millennium Project. 2008, The University of Michigan.

[21] [21] R. Stevens, D. M. Amos, L. Garrison, A. Jocuns, T. Bailey, M. Jones, and H. G. Loshbaugh. "Engineering as Lifestyle and a Meritocracy of Difficulty: Two Pervasive Beliefs Among Engineering Students and Their Possible Effects ". in American Society for Engineering Education Conference. 2007. Honolulu, Hawaii.

[22] [22] M. W. Ohland, S. D. Sheppard, G. Lichtenstein, O. Eris, D. Chachra, and R. A. Layton, "Persistence, Engagement, and Migration in Engineering Programs". Journal of Engineering Education, 2008. 97(3): p. 259-278. http://dx.doi.org/10.1002/ j.2168-9830.2008.tb00978.x

[23] [23] R. Barnett and K. Coate, "Engaging the Curriculum in Higher Education". 2005, Maidenhead: SRHE/Open University Press.
[24] [24] P. Wolf, "A model for facilitating curriculum development in higher education: A faculty-driven, datainformed, and educational developer-supported approach", in New Directions for Teaching and Learning. 2007, Wiley Periodicals, Inc.

[25] [25] G. O'Neill, "Initiating curriculum revision: exploring the practices of educational developers". International Journal for Academic Development, 2010. 15(1): p. 61-71. http://dx.doi.org/10.1080/13601440903529927

[26] [26] J. Walkington, "A process for curriculum change in engineering education". European Journal of Engineering Education, 2010. 27(2): p. 133-148. http://dx.doi.org/10.1080/ 03043790210129603

[27] [27] L. P. Grayson, "On a Methodology for Curriculum Design Engineering Education". Engineering Education, 1978. 69(3): p. 285-295.

[28] [28] Engineers Australia. "Program Accreditation". 2013 16/04/2013]; Available from: https://www.engineersaustralia. org.au/about-us/program-accreditation - standards.

\section{AUTHORS}

H. Edalatifard is a $\mathrm{PhD}$ candidate in Engineering Education at the University of Newcastle, Australia. Her field of interest is curriculum development. (e-mail: homa.edalatifard@uon.edu.au).

E. Prieto is a lecturer in Mathematics Education at the University of Newcastle, Australia. She holds a PhD in Theoretical Computer Science. From 2005 she has worked extensively in the Engineering Education field and managed an Australian Research Council funded project to identify and develop strategies for increasing engineering enrolments. (e-mail: elena.prieto@newcastle.edu.au).

This article is an extended and modified version of a paper presented at the 2013 IEEE International Conference on Teaching, Assessment and Learning for Engineering (TALE2013), held 26-29 August 2013, Bali Dynasty Resort, Kuta, Indonesia. Submitted 29 August 2013. Published as re-submitted by the authors 01 December 2013. 